\title{
ANÁLISE DAS DEPOSIÇÕES DA PULVERIZAÇÃO AÉREA SIMULANDO A APLICAÇÃO DE METARHIZIUM ANISOPLIAE (METSCH) NA CULTURA DA CANA-DE-AÇÚCAR ${ }^{1}$ )
}

\author{
HERMES GERALDO CORREA $\left({ }^{2}\right)$, CLAUDIO LUÍS MESSIAS $\left({ }^{3}\right)$, JOSÉ BARTOLOMEU HIGINO \\ DE CARVALHO ( ${ }^{4}$ e ONDINO CLEANTE BATAGLIA $\left({ }^{5}\right)$
}

\begin{abstract}
RESUMO
Aplicaçōes de inseticida biológico constituído de esporos do fungo Metarhizium anisopliae (Metsch) têm controlado satisfatoriamente a cigarrinha-da-cana, Mahanarva posticata (Stal), importante praga da cana-de-açúcar, em Alagoas. Este trabalho analisa as deposiçōes da aplicaçāo aérea na cultura da cana-de-açúcar, utilizando traçantes químicos e corantes. Foram determinados os depósitos do magnésio em fitas de papel acetinado colocadas transversalmente à linha de vôo e mediante análises de gotas recolhidas em cartões kromekote dispostos paralelamente às fitas. Nas condiçóes em que as aplicaçōes foram realizadas, verificou-se que nas faixas sobrepostas de $20 \mathrm{~m}$, a recuperaçāo foi de $44,5 \%, 50 \%$ da qual se perde no solo de modo que, no final, apenas $18 \%$ do que foi aplicado efetivamente se deposita sobre a massa vegetal da cana. Portanto, se for realizada uma aplicação do entomopatógeno nas condições do ensaio, ela deverá apresentar uma deposição efetiva de aproximadamente $1 / 5$ do total dos esporos aplicados por unidade de área.
\end{abstract}

Termos de indexação: pulverização aérea, tecnologia de aplicaçāo, defensivos agrícolas.

\section{ABSTRACT \\ AERIAL SPRAYING ANALYSIS FOR METARHIZIUM ANISOPLIAE' (METSCH) APPLICATION IN SUGARCANE CROPS}

\begin{abstract}
Biological control of spitthebug, Mahanarva posticata (Stal) in sugarcane crop has been demonstrated possible and effective. Particular conditions in Northeastern of Brazil, where this pest causes severe damage, contribute to make aerial spraying suitable. Nevertheless, some good results in pest control are alternated with unsatisfactory ones. Some doubts on aerial spray application tecnology used have arisen, since technical informations obtained in this field are scarces. This trial was carried out in Alagoas State, Brazil, in 30-7-1985 with the aim of improving the efficiency of aerial application of the above biological pesticide mentioned. This paper presents some spray deposit patterns obtained with the Brazilian aircraft, namely IPANEMA EMB 201-A. The aerial spray application using this Brazilian aircraft and lane separations of $20 \mathrm{~m}$, gave recovery of $44.5 \%$, while $60 \%$ of it was lost in the soil. There fore, only $18 \%$ of the spray application was effectively deposited on plant canopy.
\end{abstract}

Index terms: aerial spray application, aerial pest cont rol, pesticides.

$\left({ }^{1}\right)$ Trabalho apresentado no $15^{\circ}$. Congresso Brasileiro de Engenharia Agrícola, Sāo Paulo, 1986. Recebido para publicaçāo em 7 de maio de 1991 e aceito em 14 de agosto de 1992.

(2) Seção de Máquinas de Implantaçāo de Culturas e Aplicadoras de Defensivos, Divisão de Engenharia Agrícola (DEA), Instituto Agronómico đe Campinas (IAC), Caixa Postal 26, 13212-240 Jundiaí (SP).

( $\left.{ }^{3}\right)$ Departamento de Genética e Evolução, UNICAMP, Caixa Postal 1170, 13100-970 Campinas (SP).

(3) Associação de Plantadores de Cana de Alagoas (ASPLANA), Maceió (AL).

$\left({ }^{5}\right)$ Seção de Fertilidade do Solo e Nutrição de Plantas, IAC.

Bragantia, Campinas, 51(1):95-109, 1992 


\section{INTRODUÇÃO}

A cigarrinha-das-folhas, Mahanarva posticata (Stal), foi introduzida nos canaviais de Pernambuco e Alagoas por volta de 1964. Condiçōes climáticas favoráveis contribuíram para seu desenvolvimento, a ponto de, atualmente, constituir uma das principais pragas da cultura da cana, de acordo com Costa et al. (1981). Segundo os mesmos autores, o controle biológico empregando o entomopatógeno Metarhizium anisopliae (Metsch) tem apresentado, em diversos aspectos, resultados superiores àqueles obtidos com a aplicação de defensivos agrícolas organossintéticos.

As condições normalmente existentes na cultura da cana-de-açúcar, naquela região, como: plantas adultas com altura superior a $2 \mathrm{~m}$; ocupação de amplas áreas; mobilidade da cigarrinha; topografia acidentada em grande parte do terreno ocupado com a cultura, dificultando e mesmo impossibilitando o uso de tratores; coincidência do período de tratamento fitossanitário com o chuvoso, originando solos encharcados; necessidade de tratamento de extensas áreas em curtos períodos de estiagem; disponibilidade de māo-de-obra especializada em aplicaçāo aérea e existência de resultados considerados satisfatórios no controle da cigarrinha com aplicação aérea do Metarhizium, são fatores que convergem para a aplicação aérea do fungo.

$\mathrm{Na}$ campanha de 1986, foram tratados em Alagoas, utilizando a aviação agrícola, aproximadamente 30.000 ha de cana com o $M$. anisopliae.

De acordo com Carvalho $\left({ }^{6}\right)$, entomologista da Associaçāo de Plantadores de Cana de Alagoas (ASPLANA), apesar dos resultados plenamente satisfatórios para controle do inseto em laboratório, ao nível de campo, a aplicação aérea nâo tem correspondido, isto é, ao lado de áreas onde o controle da praga tem-se mostrado satisfatório, há outras onde isso não acontece, embora os fatores envolvidos sejam os mesmos.

A análise da situação levantou indagaçōes sobre a eficiência das aplicaçōes. Como no campo da aplicação aérea, em nosso meio, é notória a carência de informaçōes técnicas resultantes de ensaios específicos no meio onde o problema se apresenta,

(9) J.B.H. CARVAI HO. Informaçăo pessoal, 1986. a ASPLANA criou condiçōes para realização deste trabalho, primeiramente para atender a suas necessidades, contribuindo, com isso, também para a utilizaçāo mais eficiente do avião agrícola brasileiro.

Diversas técnicas podem ser utilizadas na análise dos depósitos das aplicações (Isler, 1963; Akesson \& Yates, 1964). Não será discutida a avaliação da cobertura proporcionada pelos depósitos de traçantes e sua distribuiçāo, pois são estimativas que colocam ênfase no caráter qualitativo das aplicações.

A técnica mais elementar de análise dos depósitos emprega a contagem das gotas coletadas por unidade de área do alvo, faz a determinação do seu diâmetro médio volumétrico e, com um fator apropriado, fornece a estimativa do volume depositado por hectare. Essa técnica requer um corante para identificação das gotas sobre o alvo.

O método, além de laborioso, apresenta a restriçāo de conduzir a erros grosseiros, quando não se tem o devido cuidado no estabelecimento do diâmetro real das gotas (Saunders et al., 1976).

Para obter resultados mais precisos, os investigadores da aplicação aérea passaram a determinar os depósitos dos defensivos diretamente sobre alvos naturais (vegetais, solos) e artificiais (placas de vidro, cartões plásticos) (Ware et al., 1969).

A análise do defensivo recolhido diretamente do alvo, porém, nem sempre é prática e possível, seja devido ao alto custo das análises, seja pelas dificuldades inerentes à recuperação do defensivo sobre os alvos, acrescidas do problema de degradação, quando esta ocorre, pela estabilidade do produto (Akesson \& Yates, 1964).

Numa etapa seguinte, passou-se a empregar processos indiretos para determinar a deposição, utilizando substâncias corantes, fluorescentes, e substâncias químicas estáveis que permitem o processamento fácil e apresentam alta sensibilidade na análise quantitativa (Yates, 1962; Yuill \& Secrest, 1966; Sharp, 1974). Tais substâncias passaram a ser conhecidas como traçantes.

Os corantes solúveis em água ou óleo, diluentes comuns dos defensivos, já foram muito usados (Akesson \& Yates, 1964; Yuill \& Secrest, 1966). Nesta técnica, o traçante colorido é removido por lavagem da superfície de amostragem, e sua concentração, determinada em colorímetro pela comparação com a densidade ótica de padrões. Todavia, a validade 
do processo depende da persistência do traçante e, no caso dos corantes, da estabilidade da cor. Entretanto, verificou-se que os traçantes corantes apresentam notável deficiência nesse particular, uma vez que a estabilidade da cor depende das condiçōes em que são utilizados, como calor, luz, hora da aplicação e estação do ano (Yates \& Akesson, 1963).

Como os traçantes fluorescentes revelam maior estabilidade do que os corantes, Yates \& Akesson (1963) elegeram, ao final de extenso trabalho, a sulfoflavina brilhante (BSF) como o traçante mais satisfatório para minuciosos ensaios de deriva, por apresentar a elevada sensibilidade requerida. Comprovaram esses autores a correlação linear entre o depósito do defensivo e o do traçante, porém verificaram que essa classe de traçantes também sofria degradação sob a luz solar (ainda que em menor grau que os corantes) e, em certos experimentos, não era possível estabelecer com precisão sua taxa de degradação, que variava com o tamanho das gotas e a natureza da superfície de amostragem (Yates et al., 1976).

Yates (1962) estudou um método mais eficiente para determinação dos depósitos da aplicação aérea utilizando sais solúveis de manganês e estrôncio, no qual os depósitos dos sais são analisados pelo espectrofotômetro de absorção atômica; além da vantagem da estabilidade das substâncias utilizadas o método apresenta uma sensibilidade muito alta.

Em face dessa evolução da técnica de determinação dos depósitos da aplicação aérea, decidiu-se, neste trabalho, utilizar como traçante o sulfato de magnésio hidratado (sal amargo), em lugar do manganês, pela sua maior sensibilidade, no método de deteç̧âo utilizado.

$O$ aspecto que se deseja ressaltar é a necessidade de a pesquisa com a aviação agrícola brasileira adotar tecnologia atualizada e precisa para solução dos seus múltiplos problemas. Outra face do trabalho é a discussão do método empregado, tendo em vista implantá-lo em nosso meio.

\section{MATERIAL E MÉTODOS}

Para ordenar, sistematizar e evitar omissões nas anotações das condições do experimento, elaborou-se uma planilha própria para uso nos ensaios de aplicação aérea.
A planilha abaixo apresenta as informações mais importantes das condiçōes do ensaio:

\section{PLANILHA DOS PARÂMETROS DA APLICAÇÃO AÉREA}

ENSAIO: Faixa de deposiçāo e recuperação da aplicação

Data: 30-7-85 Horário da aplicação: 17h20min

1. Fazenda: Surubana.

2. Proprietário: Ormindo de Mendonça Uchoa

3. Localidade: Porto Calvo, AL

4. Especificação do avião:

a) Marca: Ipanema, mod. EMB 201-A;

b) Piloto: da ASPLANA.

c) Proprietário do avião: ASPLANA.

5. Especificação do equipamento:

a) Tipo: (X) barra ( ) micronair;

b) Barra: - extensão: $10,9 \mathrm{~m}$;

- extensão efetiva: $9,45 \mathrm{~m}$;

c) Bicos de pulverização:

- marca Spraying Systems;

- série: conejet;

- tipo: D 10-46;

d) Número total de bicos na barra: 56;

e) Número de bicos fechados: 10

- localização: 3 em cada extremidade da asa;

4 sob a fuselagem

6. Especificaçōes operacionais:

a) Velocidade de vôo: $105 \mathrm{MPH}(169 \mathrm{~km} / \mathrm{h})$;

b) Orientação dos bicos: $50^{\circ}$ (contra o vôo);

c) Pressão de pulverização: $165 \mathrm{Kpa}$ (24 Psi);

d) Vazão do aparelho: 157 litros/minuto;

e) Vazão/bico: 3,4 litros/minuto;

f) Faixa de aplicação: $20 \mathrm{~m}$ (esperada);

g) Volume aplicado: 27,9 litros/hectare;

h) Comprimento médio das parcelas: $300 \mathrm{~m}$;

i) Direção de vôo: $140^{\circ}$ (contra o vento), 
j) Altura de vôo: $10 \mathrm{~m}$;

k) Informaçōes meteorológicas:

- temperatura do ar: $23^{\circ} \mathrm{C}$;

- umidade relativa do ar: $90 \%$;

- velocidade média do vento: $3,2 \mathrm{~km} / \mathrm{h}$;

- direçāo do vento: $330^{\circ}$ (sul)

( ) Sol ( ) Chuva (X) Nublado.

7. Condições de ensaio:

a) Cultura: cana-de-açúcar;

b) Espaçamento: 1,30 m;

c) Altura das plantas: $3 \mathrm{~m}$.

\subsection{Material empregado:}

a) Amostragem com solução de nigrosina $0,3 \%$ $\mathrm{p} / \mathrm{v}$ e sulfato de magnésio $2 \mathrm{~kg} / 100$ litros;

b) Fita de papel perpendicular ao vento e ao tiro + kromekote de 2 em $2 \mathrm{~m}$;

c) Fita de papel no sentido do vento para detectar a deriva + kromekote de 2 em $2 \mathrm{~m}$;

d) Fita de papel colocada dentro da cultura, no solo e nas folhas das canas;

e) Kromekote nas estacas de $4 \mathrm{em} 4 \mathrm{~m}$;

f) Kromekote nas axilas das folhas de $4 \mathrm{em} 4$ m (em amostragem dupla).

$\mathrm{Na}$ aplicação, a amostragem dos depósitos da calda contendo o sal de magnésio foi obtida em fitas de papel acetinado com $8,5 \mathrm{~cm}$ de largura e $40 \mathrm{~m}$ de extensão, colocada sobre a superfície do solo perpendicularmente ao vôo (Figura 1). Neste trabalho, para medição e contagem, as gotas foram amostradas em cartōes kromekote de 7,5 x $11 \mathrm{~cm}$ colocados no solo de $2 \mathrm{em} 2 \mathrm{~m}$, paralelamente e na extensão da fita de papel. Empregou-se como corante a nigrosina na proporção de $0,3 \% \mathrm{p} / \mathrm{v}$, para registro das gotas nos cartões.

Dentro da cultura, tendo o mesmo eixo e ainda paralelamente à amostragem anterior, colocou-se junto ao solo outra fita de papel idêntica à anterior. O paralelismo entre fitas foi estabelecido com auxílio de uma bússola magnética com precisão de leitura de $1^{\circ}$. As fitas ficaram afastadas entre si por aproximadamente $80 \mathrm{~m}$.
Ainda, dentro da cultura e paralelamente à fita colocada no solo, tomaram-se touceiras afastadas $4 \mathrm{~m}$ entre si e, em cada touceira de cana, escolheu-se um colmo, para prender, em folhas situadas no terço médio das plantas, fitas do mesmo papel acetinado com $60 \mathrm{~cm}$ de comprimento. Em cada colmo de cana selecionado, tomaram-se duas folhas em posições opostas e alinhadas com a direção do vôo, de modo a se obter a amostragem em folhas na direção de aproximação da aeronave e no sentido contrário. Colocou-se uma fita de amostragem dos depósitos da pulverização na superfície adaxial, a partir da bainha. Fez-se uma amostragem dupla, ou seja, em dupla fileira de touceiras, afastadas, respectivamente, 2,5 e $5 \mathrm{~m}$ da fita de papel colocada no solo.

Para amostragem das gotas dentro da cultura, instalaram-se cartões kromekote de 7,5 x $11 \mathrm{~cm}$, de $4 \mathrm{em} 4 \mathrm{~m}$ e a $1 \mathrm{~m}$ de altura junto da primeira linha de touceiras. Para conhecimento das gotas que se depositam sobre as folhas da cana, em duas folhas em cada touceira selecionada na primeira linha de amostragem, grampearam-se cartōes kromekote de 2,6 $x 7,5 \mathrm{~cm}$ (amostras a e b).

Nas aplicações, a linha de vôo foi assinalada por duas bandeiras de plástico (saco de adubo vazio) distanciadas entre si mais de $100 \mathrm{~m}$.

Os depósitos sobre as fitas de papel foram obtidos por meio de amostragem da solução de sulfato de magnésio hidratado na concentração de $2 \mathrm{~kg}$ por 100 litros de água. Uma área de $400 \mathrm{~cm}^{2} \mathrm{em}$ cada metro da fita foi incinerada em laboratório e dissolvida em ácido clorídrico $2 \mathrm{~N}$, sendo a concentração de $\mathrm{Mg}$ determinada com espectrofotômetro de absorção atômica. Testemunhas das fitas de papel também foram analisadas e seu teor de $\mathrm{Mg}$ determinado. Foram tomadas amostras de calda aplicada e a concentraçāo do magnésio, comprovada pela análise quantitativa.

Conhecendo-se a curva de deposição, foi feita análise da configuração das curvas com sobreposiçāo das faixas de aplicação de 10, 12, 18 e $20 \mathrm{~m}$. O método é aprovado pelo "Power and Machinery Division Standards Committee", da American Society of Agricultural Engineering (1983).

As análises de gotas do trabalho foram realizadas com auxílio de microscópio binocular com objetiva de $10 \mathrm{x}$ e ocular também $10 \mathrm{x}$, na qual foi introduzido um retículo graduado. A densidade de gotas foi determinada no projetor de perfil com ampliação de 
100x, amostrando-se em cada cartāo kromekote dez áreas de $0,5 \mathrm{~cm}^{2}(1 \times 0,5 \mathrm{~cm})$.

A aplicação foi realizada a $10 \mathrm{~m}$ acima da folhagem superior da cultura, registrando-se a umidade relativa, a temperatura ambiente e a velocidade do vento no momento da operação. A velocidade do vento foi obtida com um anemômetro de ventoinha com precisão de leitura de $0,2 \mathrm{~m} / \mathrm{s}$, e sua intensidade $\mathrm{e}$ direção, registradas pelo operador do anemômetro a cada dez minutos, num período que precedeu e que se seguiu à execução do ensaio.

\section{RESULTADOS E DISCUSSĀO}

Este trabalho foi realizado com vento de baixa velocidade e em vôo contra o vento, conforme a norma ASAE S 386.1 (American Society of Agricultural Engineers, 1983), pois o Brasil ainda não tem norma específica para calibração e determinação das faixas de aplicação.

$\mathrm{Na}$ prática, recomendam-se vôos cortando o vento, mas, em razão das condições topográficas existentes em extensas áreas da regiāo canavieira, no Norte de Alagoas, ocorrem situações em que o vôo deve ser realizado na direção do vento. Os resultados, portanto, têm aplicação prática.

Por ocasião do ensaio, a temperatura ambiente era de $23^{\circ} \mathrm{C}$ e a umidade relativa do ar, de $90 \%$. A velocidade média do vento foi de $3,2 \mathrm{~km} / \mathrm{h}$ (Quadro 1) e sua direção, $330^{\circ}$, vento sul - Figura 2.

Foram utilizados bicos D 10-46, empregados usualmente em aplicações na regiāo, já que o terreno acidentado requer vôos com $10 \mathrm{~m}$ ou mais de altura. Para compensar essa situação desvantajosa, o volume aplicado por unidade de área é aumentado, aproximando-o de 30 litros/hectare.

A análise de doze amostras das fitas de papel testemunha apresentou a média de $0,735 \mathrm{mg}$ de $\mathbf{M g}$ por metro quadrado de papel com C.V. $=6,9 \%$. Portanto, os volumes depositados foram calculados com os valores de $\mathrm{Mg}$ que excediam $0,735 \mathrm{mg}$.

$O$ quadro 2 mostra a deposição da calda em litros por hectare nas posições indicadas da faixa (1 a $30 \mathrm{~m}$ ).

Do volume total aplicado, coletou-se na fita colocada em solo limpo, o que atingiu a cultura. A análise da fita colocada sobre o solo dentro da cultura revelou o que nāo foi retido pela massa vegetativa da cana.

$\mathrm{Na}$ realidade, os dados dos quadros 2,3 e 4, relativos ao depósito em termos de volume por unidade de superfície, apresentam resultados tendo por base a concentração da calda emitida pelo bico, e não a da calda sobre o alvo, o que efetivamente é um volume menor, considerada a evaporação das gotas, sem que houvesse perda do magnésio. Do ponto de vista técnico, todavia, isso não gerou nenhum inconveniente porque os esporos do entomopatógeno persistem nas gotículas e, desde que elas sejam captadas pelo alvo, isso atende aos objetivos do trabalho.

A figura 3 apresenta o formato das curvas de deposição. Na curva obtida fora da cultura, observa-se pequena deriva da aplicação deslocando os depósitos para o lado esquerdo da faixa. Isso reflete o pequeno desvio da linha de vôo $\left(140^{\circ}\right)$ com direção do vento no momento da aplicação $\left(330^{\circ}\right)$.

Através da análise da deposição de magnésio e considerando uma curva simples de aplicação (sem sobreposição) para uma faixa ds $20 \mathrm{~m}$ (entre as posiçōes 10 e $30 \mathrm{~m}$ ), a deposição média foi de 10,5 litros/hectare, enquanto no solo, para essa mesma faixa, perderam-se em média 6,3 litros/hectare, com uma diferença de 4,2 litros/hectare, retidos pela cultura da cana. Esses números indicam uma recuperação de $40 \%$, considerando apenas a massa vegetativa da cultura como alvo.

Realizando a sobreposiçāo das faixas, conforme estabelece a norma ASAE S 386.1, têm-se os resultados do quadro 3 e as configurações das curvas encontram-se na figura 4. Na montagem dessas curvas, não se realizou a inversão entre faixas consecutivas, porque, estudando a situação gerada com a pequena deriva ocorrida, verificou-se que os resultados se afastariam da realidade.

A norma citada estabelece a adoção de faixas com amplitude igual à distância que separa os pontos da curva básica (de cada lado), onde os depósitos sāo iguais à metade do depósito máximo. Faz-se uma ressalva para os picos espúrios da curva; para contornar essa objeção, fez-se uso da média dos cinco pontos que formulam o patamar superior das deposiçōes, empregando os dados obtidos entre as posiçōes 19 e 23 do quadro 2. Nessas condiçōes, tem-se uma faixa efetiva recomendada de $10 \mathrm{~m}$. 
Quadro 1. Velocidade do vento durante o ensaio de avaliação de deposição de pulverização aérea. Porto Calvo, AL, 30-7-1985

\begin{tabular}{|c|c|c|c|c|c|c|}
\hline \multirow{2}{*}{ Posição $\left({ }^{1}\right)$} & \multirow{2}{*}{$\begin{array}{c}\text { Hora } \\
\text { da leitura }\end{array}$} & \multicolumn{4}{|c|}{ Leitura da velocidade } & \multirow{2}{*}{$\begin{array}{l}\text { Velocidade } \\
\text { média }\end{array}$} \\
\hline & & $1^{\mathrm{a}}$ & $2^{a}$ & $3^{\underline{a}}$ & Média & \\
\hline \multicolumn{2}{|l|}{$\mathbf{n}^{Q}$} & \multicolumn{4}{|c|}{$\mathrm{m} / \mathrm{min}$} & $\mathrm{km} / \mathrm{h}$ \\
\hline 1 & $14 \mathrm{~h}$ & 221 & 158 & 215 & 198,0 & 11,9 \\
\hline 2 & $14 \mathrm{~h} 10 \mathrm{~min}$ & 186 & 251 & 151 & 196,0 & 11,8 \\
\hline 3 & $14 \mathrm{~h} 20 \mathrm{~min}$ & 195 & 108 & 242 & 181,7 & 10,9 \\
\hline 4 & $14 \mathrm{~h} 30 \mathrm{~min}$ & 242 & 281 & 189 & 237,0 & 14,3 \\
\hline 5 & $14 \mathrm{~h} 40 \mathrm{~min}$ & 235 & 226 & 217 & 266,0 & 13,6 \\
\hline 6 & $14 \mathrm{~h} 50 \mathrm{~min}$ & 282 & 278 & 236 & 265,0 & 15,9 \\
\hline 7 & $15 \mathrm{~h}$ & 149 & 189 & 116 & 151,0 & 9,1 \\
\hline 8 & $15 \mathrm{~h} 10 \mathrm{~min}$ & 137 & 146 & 126 & 136,0 & 8,2 \\
\hline 9 & $15 \mathrm{~h} 20 \mathrm{~min}$ & 267 & 201 & 225 & 231,0 & 13,9 \\
\hline 10 & $15 \mathrm{~h} 30 \mathrm{~min}$ & 173 & 162 & 169 & 168,0 & 10,9 \\
\hline 11 & $15 \mathrm{~h} 40 \mathrm{~min}$ & 168 & 151 & 134 & 151,0 & 9,7 \\
\hline 12 & $15 \mathrm{~h} 50 \mathrm{~min}$ & 109 & 220 & 166 & 165,0 & 9,9 \\
\hline 13 & $16 \mathrm{~h}$ & 141 & 132 & 194 & 155,7 & 9,4 \\
\hline 14 & $16 \mathrm{~h} 10 \mathrm{~min}$ & 134 & 185 & 169 & 162,7 & 9,8 \\
\hline 15 & $16 \mathrm{~h} 20 \mathrm{~min}$ & 148 & 130 & 165 & 147,7 & 8,9 \\
\hline 16 & $16 \mathrm{~h} 30 \mathrm{~min}$ & 74 & 100 & 122 & 98,7 & 5,9 \\
\hline 17 & $16 \mathrm{~h} 40 \mathrm{~min}$ & 189 & 205 & 82 & 158,7 & 9,5 \\
\hline 18 & $16 \mathrm{~h} 50 \mathrm{~min}$ & 104 & 74 & 93 & 74,5 & 4,5 \\
\hline 19 & $17 \mathrm{~h}$ & 68 & 70 & 45 & 61,0 & 3,7 \\
\hline 20 & 17h10min & 79 & 87 & 93 & 86,4 & 5,2 \\
\hline 21 & $17 \mathrm{~h} 20 \min \left({ }^{2}\right)$ & 63 & 46 & 50 & 53,0 & 3,2 \\
\hline 22 & $17 \mathrm{~h} 30 \mathrm{~min}$ & 64 & 60 & 57 & 60,4 & 3,6 \\
\hline
\end{tabular}

(1) O número da posiçāo corresponde àquele da figura 2. $\left({ }^{2}\right)$ Horário da aplicaçāo aérea.

$\mathrm{O}$ coeficiente de variação (CV) é recomendado para análise de uniformidade da curva de deposição. Spillman (1980) coloca que CV da ordem de $30 \%$ é aceitável na maioria dos casos.

Com a sobreposição das curvas, empregando-se faixas de $10 \mathrm{~m}$, obteve-se CV de $19 \% \mathrm{e}$, por hectare, um depósito médio de 25,4 litros para um volume aplicado de 55,7 litros. Nessas condiçōes, a recuperação foi de $45,6 \%$ (veja final do quadro 3). Outro parâmetro interessante para ser analisado na curva de deposição para o intervalo da faixa adotada (10 m) é a diferença existente entre o ponto de deposição máxima e aquele de deposição mínima. Para a faixa considerada, a deposição máxima foi de 33,1 litros/hectare, na posição de $3 \mathrm{~m}$ à direita da linha de vôo, e a deposição mínima, 18,1 litros/hectare, obtida a $4 \mathrm{~m}$ debaixo da asa esquerda (Quadro 3). Foi considerada como amplitude total (AT) a porcentagem da deposição máxima que excede a mínima. Para a faixa de $10 \mathrm{~m}$, a AT foi de $83 \%$. 


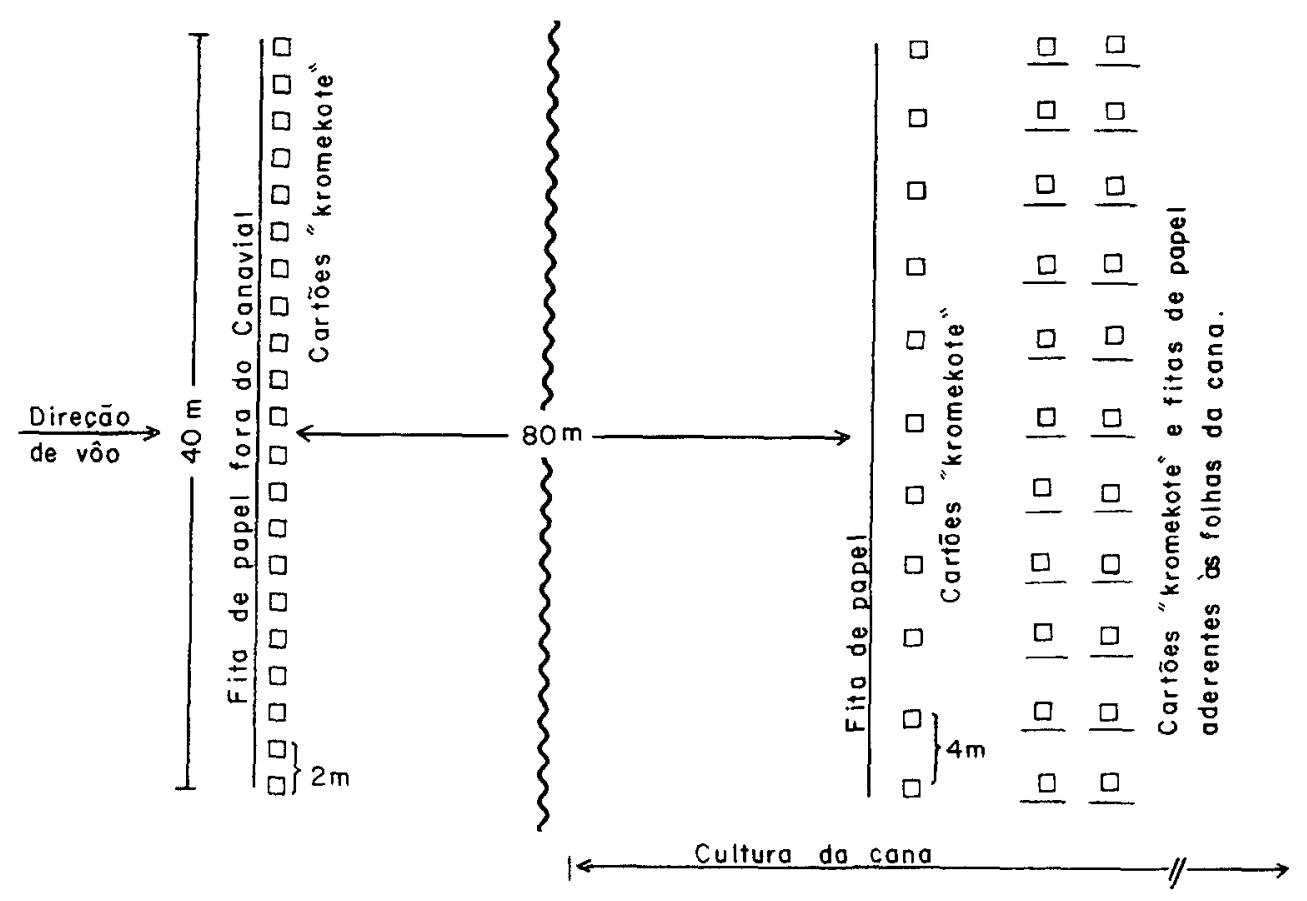

Figura 1. Esquema da distribuição de fitas e cartões em lavoura de cana para estudo das deposições resultantes da pulverização aérea. Porto Calvo, AL, 1985.

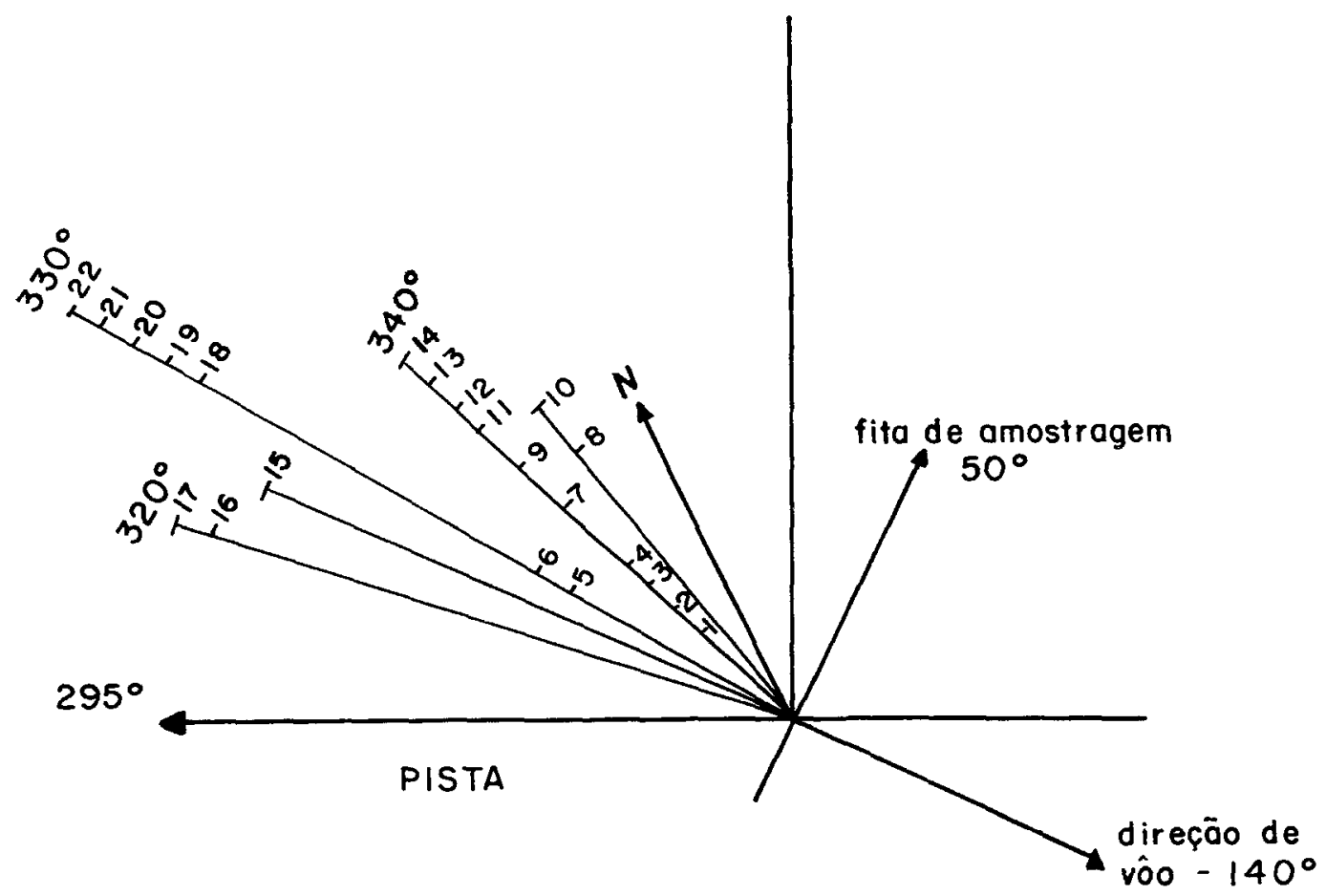

Figura 2. Direção de vôo durante a aplicação aérea visando ao estudo de deposição.

Porto Calvo, AL, 1985. 
Quadro 2. Volume de calda (1/ha), depositado em faixas de papel colocadas perpendicularmente ao vento e à linha de vôo, mediante pulverização aérea. Porto Calvo, AL, 1985

\begin{tabular}{|c|c|c|c|c|c|c|c|c|c|c|c|c|c|c|c|}
\hline \multirow{2}{*}{ Volume } & \multicolumn{15}{|c|}{ Pontos de amostragem na faixa (metros) } \\
\hline & 1 & 2 & 3 & 4 & 5 & 6 & 7 & 8 & 9 & 10 & 11 & 12 & 13 & 14 & 15 \\
\hline $1 /$ ha & & . & . & & & & - & 1/ha & & & & & & & 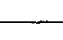 \\
\hline $\begin{array}{l}\text { Total depositado } \\
\text { (solo sem a cultura) }\end{array}$ & - & - & - & 5,4 & 4,6 & 5,8 & 7,0 & 4,1 & 6,4 & 5,7 & 6,1 & 6,0 & 8,5 & 8,8 & 11,9 \\
\hline $\begin{array}{l}\text { Diferença retida na massa } \\
\text { vegetal da cultura) }\end{array}$ & - & - & - & - & - & - & 0,7 & $-0,2$ & 4,8 & 4,0 & 3,8 & 2,5 & 0,0 & $-0,6$ & 4,3 \\
\hline
\end{tabular}

Volume

Pontos de amostragem na faixa (metros)

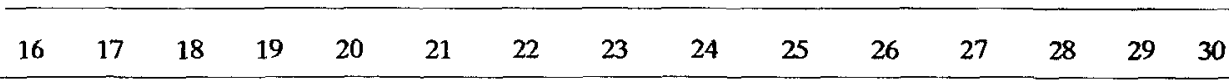

1/ha

Total depositado

(solo sem a cultura)

Depositado no solo

dentro da cultura

Diferença (retida na massa

vegetal da cultura)

\begin{tabular}{rrrrrrrrrrrrrrr}
11,2 & 17,6 & 14,5 & 24,2 & 22,4 & 16,5 & 23,6 & 21,9 & 12,4 & 5,5 & 1,1 & 1,1 & 0,9 & 0,7 & 0,4 \\
6,8 & 6,8 & 4,6 & 9,7 & 17,7 & 8,9 & 16,2 & 9,5 & 5,6 & 4,9 & 2,5 & 1,2 & 1,0 & 1,9 & 1,2 \\
4,4 & 10,8 & 9,9 & 14,5 & 4,7 & 7,6 & 7,4 & 12,4 & 6,8 & 0,6 & $-1,4$ & $-0,1$ & $-0,1$ & $-1,2$ & $-0,8$ \\
\hline
\end{tabular}

Essa informação, importante para aplicação de inseticidas e fungicidas, em especial quando a eficácia do tratamento depende de depósito uniformemente distribuído, é fundamental para a aplicaçāo de herbicidas, quando subdosagens ou dosagens fitotóxicas são causas de maior preocupação.

Ainda com relação à faixa de $10 \mathrm{~m}$ (Quadro 3), na coluna à direita da coluna de deposiçāo, são apresentados os desvios percentuais da média. À distância de $4 \mathrm{~m}$ sob a asa esquerda obteve-se $-28,7 \%\left(^{7}\right)$ e a $3 \mathrm{~m}$ sob a asa direita, $30,3 \%$. Para faixas de $12 \mathrm{~m}$, já se observam alteraçōes notórias na deposição. A amplitude total passou a correspònder a $215 \%$ e o coeficiente de variaçāo aumentou para $34,4 \%$, ultrapassando valores aceitáveis (Spillman, 1980).

$\left.{ }^{7}\right)$ Valores negativos revelam percentuais de deposiçōes inferiores à média.
Considerando faixas de aplicação de 18 e 20 $\mathrm{m}$, os valores analisados se deterioram a ponto de, na curva das faixas de $18 \mathrm{~m}$, ter-se no ponto de deposição máxima, a $2 \mathrm{~m}$ sob a asa direita, depósito 5,6 vezes superior àquele obtido no ponto de deposição mínima (posição $6 \mathrm{~m}$ sob a asa direita).

Pelo quadro 2 , já se verificou que, para faixas de $20 \mathrm{~m}$, apenas $40 \%$ do volume depositado sobre a cultura ficaram retidos pela massa vegetativa. Mas, para essa amplitude da faixa, o quadro 3 revela que somente $44,5 \%$ do que é aplicado se deposita na área tratada, perdendo-se o restante por deriva. Portanto, nessas condiçōes, apenas $17,8 \%$ do total aplicado está efetivamente sendo retido pelo alvo, que no caso é a massa vegetal da cana.

A preocupaçāo de obter maior rendimento operacional nas aplicações aéreas gera interesse por faixas mais amplas, mas a adoção dessas faixas com amplitude superior àquela tecnicamente recomendada aumentou a irregularidade na curva de deposição. 
Faixas de 10 e $12 \mathrm{~m}$ atenderam (com a regulagem adotada) às recomendaçōes técnicas, enquanto as de 18 e $20 \mathrm{~m}$, que usualmente interessam ao esquema de pulverização adotado na região, estão fora de recomendação.

No quadro 4, que apresenta os volumes de deposição obtidos sobre o papel preso à parte basal das folhas, o maior depósito (5,6 litros/hectare) foi obtido na posição de $24 \mathrm{~m}$, sob a asa direita da aeronave. Para assimilar os dados desse quadro, deve-se considerar que as folhas de cana-de-açúcar têm um ângulo de inserção no colmo. Em vista disso, a superfície da folha na sua parte basal é maior do que a área de sua projeção horizontal, de modo que seus depósitos por unidade de área ficam reduzidos em relação àqueles obtidos em superfícies horizontais. Não se fez a determinaçāo desse ângulo no campo, mas, admitindo um ângulo médio de $30^{\circ}$, a projeção horizontal da superfície foliar fica reduzida à metade.
O resultado da análise de gotas amostradas em cartōes kromekote colocados no solo transversalmente à linha de vôo encontra-se no quadro 5 . O diâmetro mediano numérico (DMN) para faixa de 2 a $24 \mathrm{~m}$ foi em média de $134 \mu \mathrm{m}$. O diâmetro mediano volumétrico (DMV), nas mesmas condiçōes, foi de $365 \mu \mathrm{m}$ e o diâmetro médio volumétrico (DV) apresentou em média $229 \mu \mathrm{m}$.

O coeficiente de homogeneidade do espectro de gotas $(\mathrm{CH})$ é obtido da razāo, expressa em porcentagem do diâmetro de $25 \%$ do número das gotas, e o diâmetro de $75 \%$ do mesmo número.

A densidade média de gotas (DG) obtida foi de 20 gotas por centímetro quadrado. Na última linha do quadro 5 , são apresentados com restriçōes os volumes depositados e calculados segundo a DG e o DV. Esses volumes têm apenas expressão referencial, considerando a dificuldade para a precisa determinação dos diâmetros das gotas em amostras obtidas da aplicação aérea, conforme Saunders et al. (1976) já apontaram.

Quadro3. Volume depositado com justaposição de faixas de 10,12, 18 e $20 \mathrm{~m}$. Deposiçōes obtidas por pulverização aérea, em vôo contra o vento e sem inversāo da curva. Porto Calvo, AL, 1985. Asa esquerda

\begin{tabular}{|c|c|c|c|c|c|c|c|c|}
\hline \multirow{2}{*}{$\frac{\text { Distância }}{\mathbf{m}}$} & \multicolumn{2}{|c|}{ Faixa de $10 \mathrm{~m}$} & \multicolumn{2}{|c|}{ Faixa de $12 \mathrm{~m}$} & \multicolumn{2}{|c|}{ Faixa de $18 m$} & \multicolumn{2}{|c|}{ Faixa de $20 \mathrm{~m}$} \\
\hline & litros/ha & $\begin{array}{l}\text { desvio } \% \\
\text { da } \bar{x}\end{array}$ & litros/ha & $\begin{array}{l}\text { desvio } \\
\text { da } \bar{x}\end{array}$ & litros/ha & $\underset{\text { da } \overline{\mathbf{x}}}{\text { desvio }} \%$ & litros/ha & $\begin{array}{c}\text { desvio } \% \\
\text { da } \bar{x}\end{array}$ \\
\hline 15 & 22,0 & 13,4 & 22,9 & 11,7 & 26,5 & 90,6 & 10,1 & 19,2 \\
\hline 14 & 18,1 & 28,7 & 20,7 & 1,0 & 18,2 & 30,9 & 6,9 & $-44,8$ \\
\hline 13 & 25,7 & 1,2 & 31,2 & 52,2 & 12,5 & $-10,1$ & 8,1 & $-35,2$ \\
\hline 12 & 19,5 & $-23,2$ & 26,5 & 29,3 & 5,2 & $-62,6$ & 5,0 & $-60,0$ \\
\hline 11 & 31,3 & 23,2 & 22,9 & 11,7 & 7,5 & $-46,0$ & 7,1 & $-43,2$ \\
\hline 10 & 28,5 & 12,2 & 29,3 & 42,9 & 6,6 & $-52,5$ & $6,1\left(^{2}\right)$ & $-51,2$ \\
\hline 9 & 22,6 & $-11,0$ & 28,0 & 36,6 & $6,8\left(^{2}\right)$ & $-51,1$ & 6,1 & $-51,2$ \\
\hline 8 & 29,6 & 4,7 & 18,4 & $-10,2$ & 6,4 & $-53,9$ & 6,0 & $-52,0$ \\
\hline 7 & 33,1 & 30,3 & 14,0 & $-31,7$ & 8,5 & $-38,8$ & 8,5 & $-32,0$ \\
\hline 6 & 26,6 & 4,7 & $9,9\left(^{2}\right)$ & $-51,7$ & 8,8 & $-36,7$ & 8,8 & $-29,6$ \\
\hline 5 & $22,0\left(^{2}\right)$ & $-13,4$ & 15,7 & $-23,4$ & 11,9 & $-14,4$ & 11,9 & $-4,8$ \\
\hline 4 & 18,1 & $-28,7$ & 17,5 & $-14,6$ & 11,2 & $-19,4$ & 11,2 & $-10,4$ \\
\hline 3 & 25,7 & 1,2 & 22,9 & 11,7 & 17,6 & 26,6 & 17,6 & 40,8 \\
\hline 2 & 19,5 & $-23,2$ & 20,7 & 1,0 & 14,5 & 4,3 & 14,5 & 16,0 \\
\hline 1 & 31,3 & 23,2 & 31,2 & 52,2 & 24,2 & 74,1 & 24,2 & 93,6 \\
\hline $0\left(^{1}\right)$ & 28,5 & 12,2 & 26,5 & 29,3 & 22,4 & 61,1 & 22,4 & 79,2 \\
\hline
\end{tabular}




\begin{tabular}{|c|c|c|c|c|c|c|c|c|}
\hline \multirow{2}{*}{$\frac{\text { Distância }}{\mathbf{m}}$} & \multicolumn{2}{|c|}{ Faixa de $10 \mathrm{~m}$} & \multicolumn{2}{|c|}{ Faixa de $12 \mathrm{~m}$} & \multicolumn{2}{|c|}{ Faixa de $18 \mathrm{~m}$} & \multicolumn{2}{|c|}{ Faixa de $20 \mathrm{~m}$} \\
\hline & litros/ha & $\begin{array}{l}\text { desvio } \\
\text { da } \bar{x}\end{array}$ & litros/ha & $\underset{\text { da } \bar{x}}{\text { desvio }} \%$ & litros/ha & $\begin{array}{l}\text { desvio } \% \\
\text { da } \overline{\mathbf{x}}\end{array}$ & litros/ha & $\begin{array}{l}\text { desvio } \\
\text { da } \bar{x}\end{array}$ \\
\hline $0\left(^{1}\right)$ & 28,5 & 12,2 & 26,5 & 29,3 & 22,4 & 61,1 & 22,4 & 79,2 \\
\hline 1 & 22,6 & $-11,0$ & 22,9 & 11,7 & 19,2 & 38,1 & 16,5 & 32,0 \\
\hline 2 & 29,6 & 16,5 & 29,3 & 42,9 & 29,0 & 108,6 & 23,6 & 88,8 \\
\hline 3 & 33,1 & 30,3 & 28,0 & 36,6 & 26,5 & 90,6 & 24,6 & 96,8 \\
\hline 4 & 26,6 & 4,7 & 18,4 & $-10,4$ & 18,2 & 30,9 & 17,8 & 42,4 \\
\hline 5 & $22,0\left(^{2}\right)$ & 13,4 & 14,0 & $-31,7$ & 12,5 & $-10,1$ & 10,1 & $-19,2$ \\
\hline 6 & 18,1 & 28,7 & $9,9\left(^{2}\right)$ & $-51,7$ & 5,2 & $-62,6$ & 6,9 & $-44,8$ \\
\hline 7 & 25,7 & 1,2 & 15,7 & $-23,4$ & 7,5 & $-46,0$ & 8,1 & $-35,2$ \\
\hline 8 & 19,5 & $-23,2$ & 17,5 & $-14,6$ & 6,6 & $-52,5$ & 5,0 & $-60,0$ \\
\hline 9 & 31,3 & 23,2 & 22,9 & 11,7 & $6,8\left(^{2}\right)$ & $-51,1$ & 7,1 & $-43,2$ \\
\hline 10 & 28,5 & 12,2 & 20,7 & 1,0 & 6,4 & $-53,9$ & $6,1\left(^{2}\right)$ & $-51,2$ \\
\hline 11 & 22,6 & $-11,0$ & 31,2 & 52,2 & 8,5 & $-38,8$ & 6,1 & $-51,2$ \\
\hline 12 & 29,6 & 16,5 & 26,5 & 29,3 & 8,5 & $-36,7$ & 6,0 & $-52,0$ \\
\hline 13 & 33,1 & 30,3 & 22,9 & 11,7 & 11,9 & $-14,4$ & 8,5 & $-32,0$ \\
\hline 14 & 26,6 & 4,7 & 29,3 & 42,9 & 11,2 & $-19,4$ & 8,8 & $-29,6$ \\
\hline 15 & 22,0 & $-13,4$ & 28,0 & 36,6 & 17,6 & 26,6 & 11,9 & $-4,8$ \\
\hline \multicolumn{3}{|c|}{$\mathbf{M}=25,41 / \mathrm{ha}$} & \multicolumn{2}{|c|}{$\mathrm{M}=20,5 \mathrm{l} / \mathrm{ha}$} & \multicolumn{2}{|c|}{$M=13,91 / \mathrm{ha}$} & \multicolumn{2}{|c|}{$\mathbf{M}=12,5 \mathrm{l} / \mathrm{ha}$} \\
\hline \multicolumn{3}{|c|}{$\mathrm{CV}=19,4 \%$} & \multicolumn{2}{|c|}{$\mathrm{CV}=34,4 \%$} & \multicolumn{2}{|c|}{$C V=54,2 \%$} & \multicolumn{2}{|c|}{$C V=54,0 \%$} \\
\hline \multicolumn{3}{|c|}{$\mathrm{AT}=82,9 \%$} & \multicolumn{2}{|c|}{$\mathrm{AT}=215,2 \%$} & \multicolumn{2}{|c|}{$\mathrm{AT}=457,7 \%$} & \multicolumn{2}{|c|}{$\mathrm{AT}=392,0 \%$} \\
\hline \multicolumn{3}{|c|}{$\mathrm{Va}=55,7 \mathrm{l} / \mathrm{ha}$} & \multicolumn{2}{|c|}{$\mathrm{Va}=46,4 \mathrm{l} / \mathrm{ha}$} & \multicolumn{2}{|c|}{$\mathrm{Va}=31,01 / \mathrm{ha}$} & \multicolumn{2}{|c|}{$\mathrm{Va}=27,91 / \mathrm{ha}$} \\
\hline \multicolumn{3}{|c|}{$\operatorname{Rec}=45,6 \%$} & \multicolumn{2}{|c|}{$\operatorname{Rec}=44,2 \%$} & \multicolumn{2}{|c|}{$\mathrm{Rec}=44,8 \%$} & \multicolumn{2}{|c|}{$\operatorname{Rec}=44,5 \%$} \\
\hline
\end{tabular}

(1) Centro de linha đe vôo đa aeronave. ( ${ }^{2}$ ) Extremos da faixa de aplicação utilizada.

$\mathrm{M}=$ volume médio depositado na faixa. $\mathrm{CV}=$ coeficiente de variação dos volumes depositados na faixa. AT = amplitude total. $\mathrm{Va}=$ Volume aplicado na faixa por cálculo utilizando vazão, velocidade do aparelho e largura da faixa. Rec $=$ recuperação relacionando $\mathrm{M}$ e Va. $\overline{\mathbf{x}}=$ média.

Comparando, no quadro 2, o volume total depositado com os resultados do mesmo experimento na última linha do quadro 5 , verifica-se uma discrepância porque, na faixa 4 a $24 \mathrm{~m}$, através da análise de gotas (Quadro 5), tem-se um depósito médio de 16,7 litros/hectare quando a análise química (Quadro 2) para a mesma faixa indica a média de 11,6 litros/hectare. A análise de gotas deveria apresentar diâmetros inferiores devido à evaporação das gotas: isso não ocorreu, mesmo tendo-se o cuidado de, no processamento, aplicar a correção do fator de espalhamento adequado a cada população.
Na posição $22 \mathrm{~m}$ (Quadro 5), tem-se um volume de 52 litros/hectare, enquanto na mesma posição (Quadro 2) estão registrados 23,6 litros; a discrepância, portanto, é grande, mostrando até incoerência, uma vez que a evaporação foi superior àquela apresentada na análise química.

Outra parte da explicação para esta discrepância, além daquela apontada por Saunders et al. (1976), está no fato de que o volume é uma função exponencial do diâmetro; assim, os erros que possam ocorrer na sua determinação repercutem e com freqüência tornam-se grosseiros. 
Quadro 4. Volumes da deposição da calda aplicada em pulverização aérea segundo a análise do traçante no papel preso às folhas de cana. Porto Calvo, AL, 1985

\begin{tabular}{|c|c|c|c|c|c|c|c|c|c|c|c|}
\hline \multirow{2}{*}{\multicolumn{2}{|c|}{ Amostra }} & \multicolumn{10}{|c|}{ Distância transversal (m) } \\
\hline & & 4 & 8 & 12 & 16 & 20 & 24 & 28 & 32 & 36 & 40 \\
\hline \multirow[t]{3}{*}{ A } & $\mathrm{C}$ & 1,0 & 0,6 & 1,5 & $-0,1$ & 4,0 & 1,4 & 1,5 & - & 2,3 & 1,3 \\
\hline & $\mathbf{F}$ & 0,4 & 0,3 & 0,8 & 1,7 & 2,1 & 0,5 & 3,2 & 1,1 & 2,1 & 2,4 \\
\hline & $\overline{\mathbf{x}}$ & 0,7 & 0,4 & 1,2 & 0,8 & 3,0 & 0,9 & 2,4 & 1,1 & 2,2 & 1,8 \\
\hline \multirow[t]{3}{*}{$\mathbf{B}$} & $\mathrm{C}$ & - & - & - & 4,9 & 6,4 & 12,6 & 2,7 & 1,3 & 2,4 & $-0,4$ \\
\hline & $\mathbf{F}$ & - & - & - & 3,6 & 3,3 & 8,3 & - & 1,3 & 1,4 & 0,4 \\
\hline & $\overline{\mathbf{x}}$ & & & & 4,2 & 4,8 & 10,4 & 2,7 & 1,3 & 1,9 & 0,0 \\
\hline \multicolumn{2}{|c|}{ Média final } & & & & 2,5 & 3,9 & 5,6 & 2,5 & 1,2 & 2,1 & 0,9 \\
\hline
\end{tabular}

C: contra o vôo; F: a favor do vôo; $\bar{x}$ : média.

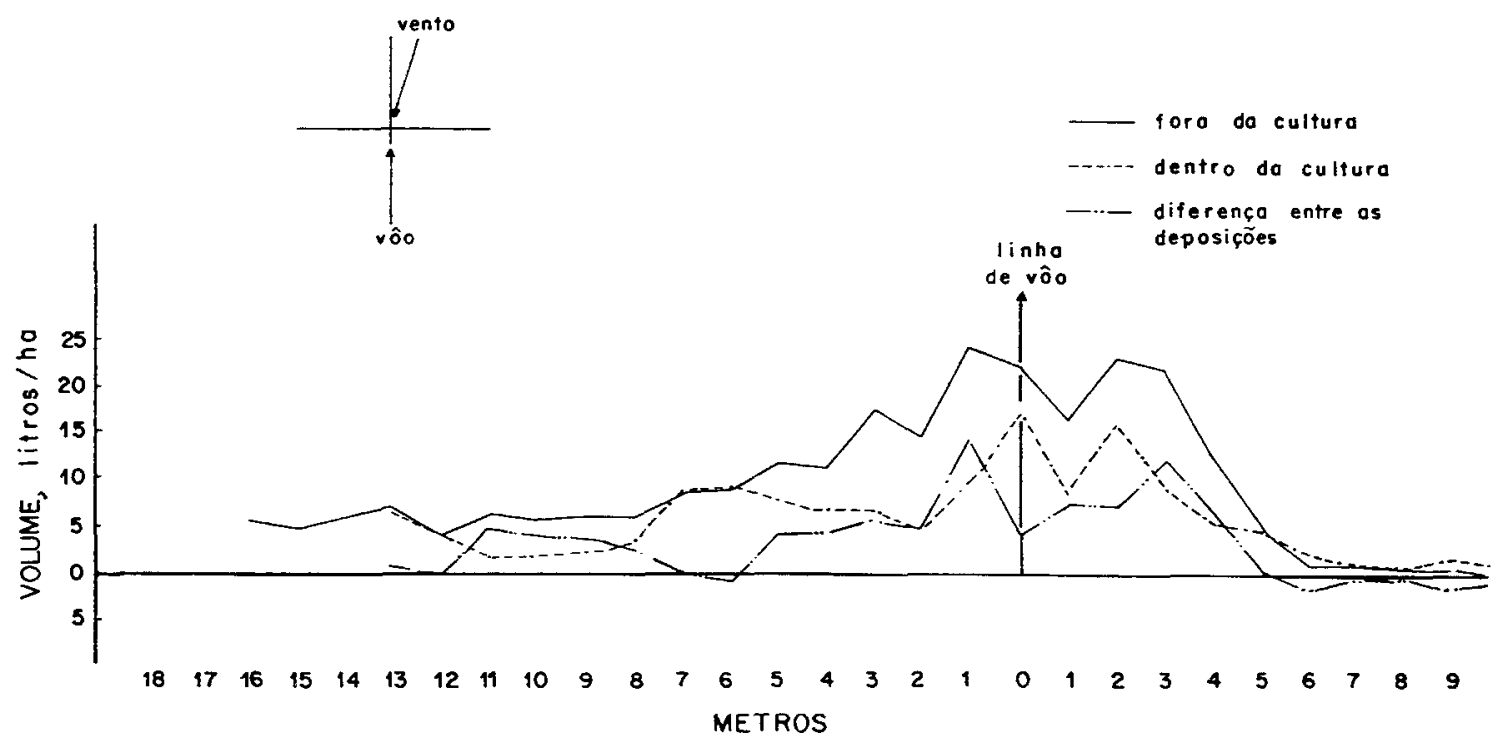

Figura 3. Curvas de deposição da pulverização aérea dentro e fora de lavoura de cana-de-açúcar.

Porto Calvo, AL, 1985. 


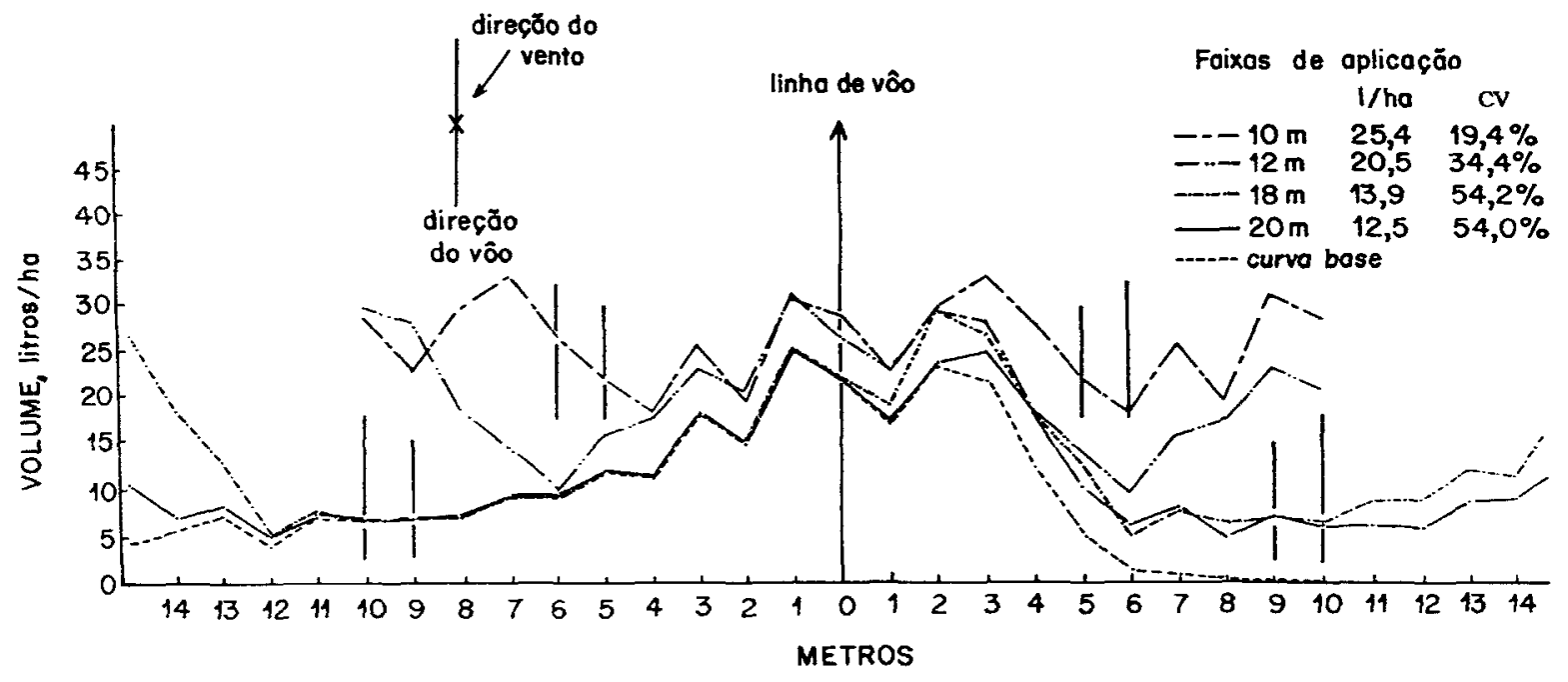

Figura 4. Curvas de deposição da pulverização aérea com sobreposição de faixas sem inversāo.

Porto Calvo, AL, 1985.

Quadro 5. Parâmetros das gotas obtidas na pulverização aérea e depositadas sobre papel kromekote colocado sobre o solo perpendicularmente à linha de vôo $\left({ }^{1}\right)$ Porto Calvo, AL, 1985

\begin{tabular}{|c|c|c|c|c|c|c|c|c|c|c|c|c|c|c|}
\hline \multirow{2}{*}{ Parâmetros } & \multicolumn{12}{|c|}{ Posição de amostragem } & \multirow{2}{*}{ Méđia } & \multirow{2}{*}{$\mathrm{CV} \%$} \\
\hline & $2 \mathrm{~m}$ & $4 m$ & $6 \mathrm{~m}$ & $8 \mathrm{~m}$ & $10 \mathrm{~m}$ & $12 \mathrm{~m}$ & $14 \mathrm{~m}$ & $16 \mathrm{~m}$ & $18 \mathrm{~m}$ & $20 \mathrm{~m}$ & $22 \mathrm{~m}$ & $24 \mathrm{~m}$ & & \\
\hline D.M.N., $\mu \mathrm{m}$ & 100 & 137 & 111 & 93 & 85 & 93 & 123 & 145 & 171 & 200 & 241 & 111 & 134 & 36 \\
\hline D.M.V., $\mu \mathrm{m}$ & 295 & 375 & 380 & 321 & 519 & 400 & 420 & 350 & 330 & 415 & 410 & 168 & 365 & 23 \\
\hline D.V., $\mu \mathrm{m}$ & 197 & 204 & 236 & 197 & 242 & 216 & 259 & 240 & 248 & 245 & 314 & 153 & 229 & 18 \\
\hline Litro/hectare & 4,6 & 4,8 & 5,5 & 5,2 & 11,3 & 10,0 & 12,7 & 16,6 & 40,7 & 23,1 & 52 & 2,1 & 15,7 & 100 \\
\hline
\end{tabular}

(1) Eixo de vôo a $20 \mathrm{~m}$ com vento soprando a $330^{\circ}$. Aplicação realizada em $30-7-1985$, às 17h20min, na Fazenda Surubana, utilizando bicos $D$ 10/46.

D.M.N. = diâmetro mediano numérico;

D.M.V = diâmetro međiano volumétrico;

D.V. = diâmetro volumétrico médio;

C.H. $=$ coeficiente de homogeneidađe $=\frac{\text { diâm. } 25 \% \text { do } n^{\circ}}{\text { diâm. } 75 \% \text { do } n^{\circ}} \times 100$;

D.G. = densidade de gotas $/ \mathrm{cm}$;

Litro/hectare $=$ volume depositado por cálculo, utilizando D.V. e D.G. 
Todavia, a análise das gotas continua sendo importante parâmetro das aplicaçōes para a previsāo e explicação do comportamento físico e biológico dos tratamentos realizados.

A análise das gotas amostradas dentro da cultura com espaço vertical descoberto e à altura de $1 \mathrm{~m}$ do solo é apontada no quadro 6; pela sua confrontação com o quadro 7 , ambos obtidos dentro da cultura, obtém-se informação valiosa: o quadro 7 mostra que as gotas captadas pelas folhas situadas no terço mediano da planta são menores do que aquelas que caem sobre a cultura. São também menores que aquelas filtradas pela folhagem da cana disposta acina da posição de amostragem (1 m) (Quadro 6).

Verificou-se, portanto, maior eficiência de captação da folhagem mediana para as gotas menores do espectro aplicado, ao passo que as maiores, que penetram no intervalo da cultura, perdem-se no solo. Isso é muito significativo porque o volume das gotas que estão penetrando nos intervalos vazios da cultura e perdendo-se no solo (DV média - $325 \mu \mathrm{m}$, Quadro 6) é mais de oito vezes superior àquele retido pelas folhas com gotas de DV médio $=158 \mu \mathrm{m}$. Por conseguinte, pouca eficiência se tem quando se aplicam gotas com diâmetros avantajados como aquelas empregadas neste ensaio, porque o que não é retido pela primeira camada superior das folhas perde-se no solo. Outra indicação que o tamanho das gotas empregadas na aplicação foi maior do que deveria está na pequena expansão da faixa útil de aplicação (10 m) (Quadro 3); o uso de gotas com menor diâmetro poderia proporcionar maior expansão à faixa.

Quadro 6. Parâmetros das gotas obtidas na pulverização aérea e depositadas em cartōes kromekote colocados dentro da cultura a $1 \mathrm{~m}$ do solo e nos espaços descobertos de folhas $\left({ }^{1}\right)$ Porto Calvo, AL, 1985

\begin{tabular}{|c|c|c|c|c|c|c|c|c|}
\hline \multirow{2}{*}{ Parâmetro } & \multicolumn{7}{|c|}{ Posição de amostragem } & \multirow{2}{*}{ Média } \\
\hline & $0 \mathrm{~m}$ & $4 \mathrm{~m}$ & $8 \mathrm{~m}$ & $12 \mathrm{~m}$ & $16 \mathrm{~m}$ & $20 \mathrm{~m}$ & $24 \mathrm{~m}$ & \\
\hline D.M.N., $\mu \mathrm{m}$ & 218 & 249 & 317 & 185 & 211 & 199 & 195 & 225 \\
\hline D.M.V., $\mu \mathrm{m}$ & 294 & 405 & 465 & 620 & 430 & 350 & 480 & 435 \\
\hline D.V., $\mu \mathrm{m}$ & 274 & 318 & 404 & 376 & 308 & 288 & 309 & 325 \\
\hline C.H., \% & 59 & 50 & 57 & 34 & 41 & 47 & 43 & 47 \\
\hline D.G. & 2,2 & 3,2 & 1,8 & 1,4 & 9,6 & 14,2 & 18,8 & 7,3 \\
\hline Litro/hectare & 2,4 & 5,4 & 6,2 & 4,0 & 14,7 & 17,7 & 29,0 & 11,3 \\
\hline
\end{tabular}

${ }^{1}$ ) Eixo de vôo a $20 \mathrm{~m}$ com vento soprando a $330^{\circ}$. Aplicação realizada em $30-7-1985$, às $17 \mathrm{~h} 20 \mathrm{~min}$, na Fazenda Surubana, utilizando bicos D $10 / 46$.

D.M.N. = điâmetro mediano numérico;

D.M.V = diâmetro mediano volumétrico;

D.V. = diâmetro volumétrico médio;

C.H. $=$ coeficiente de homogeneidade $=\frac{\text { diâm. } 25 \% \text { do } n^{\circ}}{\text { diâm. } 75 \% \text { do } n^{0}} \times 100$,

D.G. = densidade de gotas/cm;

Litro/hectare $=$ volume depositado por cálculo, utilizando D.V. e D.G. 
Quadro 7. Parâmetros das gotas obtidas na pulverização aérea e depositadas em cartōes kromekote presos às folhas da altura mediana da planta. Porto Calvo, AL, 1985

\begin{tabular}{lcccccr}
\hline & \multicolumn{5}{c}{ Posição da amostragem } & Média \\
\cline { 2 - 6 } & $8 \mathrm{~m}$ & $16 \mathrm{~m}\left({ }^{1}\right)$ & $20 \mathrm{~m}$ & $24 \mathrm{~m}(\mathrm{a})$ & $24 \mathrm{~m}(\mathrm{~b})\left(^{2}\right)$ & \\
\hline D.M.N., $\mu \mathrm{m}$ & 89 & 86 & 67 & 96 & 142 & 90 \\
D.M.V., $\mu \mathrm{m}$ & 247 & 193 & 110 & 221 & 218 & 192 \\
D.V., $\mu \mathrm{m}$ & 174 & 145 & 102 & 167 & 202 & 158 \\
C.H., \% & 29 & 66 & 42 & 37 & 58 & 46 \\
D.G., $\mathbf{n}^{\mathrm{Q}}$ & $8, \mathrm{u}$ & 8,0 & 6,4 & 10,0 & 6,0 & 7,7 \\
Litro/hectare & 2,2 & 1,3 & 0,4 & 2,4 & 2,6 & 1,8 \\
\hline
\end{tabular}

(1) Perdeu-se amostragem dos cartões kromekote de 0,4 e $12 \mathrm{~m}$. ( ${ }^{2}$ ) Perdeu-se, por precipitaçāo imprevista, a $2^{a}$ amostragem (b), das demais distâncias.

\section{CONCLUSŌES}

1. As recuperaçōes obtidas por intermédio dos diâmetros das gotas e sua densidade por unidade de área apresentaram resultados com grande discrepância e até incoerência com aqueles obtidos por meio da análise química da deposição de magnésio, que se reconhece ser mais precisa.

2. O espectro de gotas utilizado apresentou diâmetro mediano volumétrico (DMV) superior ao adequado, considerando que a amplitude da faixa ficou reduzida a $10 \mathrm{~m}$.

3. A amostragem de gotas sobre as folhas da cana confirmou a necessidade de gotas menores para aumentar o percentual captado pela folhagem.

4. Em vista desses resultados, recomendam-se para esse tipo de aplicação gotas com DMV menores.

5. Para faixas com amplitude de $20 \mathrm{~m}$, a recuperação obtida com sobreposiçạo de faixas foi de $44,5 \%$, mas, desse total, $60 \%$ se perdeu no solo de modo que, no final, apenas $18 \%$ do que foi aplicado efetivamente se depositou sobre a massa vegetal da cana.

6. A calda deverá ter aproximadamente cinco vezes $(5,6)$ a concentração de esporos do entomopatógeno desejada sobre a massa vegetal da cana, uma vez que $4 / 5$ da calda aplicada estão-se perdendo.

\section{AGRADECIMENTOS}

Ao Professor Tomomassa Matuo e ao Dr. Cláudio Alves Moreira, pelas valiosas observaçōes, que muito contribuíram para a redação deste trabalho, e ao Auxiliar de Pesquisa Florisval da Silva Santos, pelo labor e cuidado no processamento dos dados.

\section{REFERÊNCIAS BIBLIOGRÁFICAS}

AKESSON, N.B. \& YATES, W.E. Problems relating to application of agricultural chemicals and resulting drift residues. Annual Review of Entomology, Palo Alto, 9:285-318, 1964.

AMERICAN SOCIETY OF AGRICULTURAL ENGINEERS. Calibration and distribution pattern testing of agricultural aerial application equipment ASAE Standard: ASAE S 386.1. Agricultural Engineers Yearbook, St. Joseph, p.252-254, 1983.

COSTA, J.M.B.; BARBOSA, G.V.S.; FERREIRA, J.L.C; LIRA, P.R.M.; DORIA, A.E. \& MENDONÇA, A.F. Controle integrado de cigarrinha da folha Mahanarva posticata, Stal (Hom: Cercopidae) no Estadó de Alagoas. In: CONGRESSO NACIONAL DA SOCIEDADE DE TÉCNICOS ACUCAREIROS DO BRASIL, 2., e SIMPÓSIO LATINO-AMERICANO SOBRE MODALIDADES DE FINANCIAMENTO À PRO. DUÇÃO DE ENERGIA RENOVÁVEL, 1., , Rio de Janeiro, 1981. Anais. Rio de Janeiro, STAB, 1981. v.2, p.475-495.

ISLER, D.A. Methods for evaluating coverage and drop size in forest spraying. Transactions of the ASAE. St. Joseph, 6:231$-233,1963$. 
SAUNDERS, W.J.; TATE, R.W. \& WARE, G.W. Analysis of aerial sprays from conventional and drift reduction nozzles. St. Joseph, American Society of Agricultural Engineers, 1976. 13p. (Paper, 1062)

SHARP, R.B. Spray deposit measurements by fluorescence. Pesticide Science, Oxford, 5:197-209, 1974.

SPILLMAN, J.J. The efficiency of aerial spraying. Aeronantical Journal, London, 84(83):60-69, 1980.

WARE, G.W.; APPLE, EJ.; CAHILL, W.P.; GERHARDT, P.D. \& FROST, K.R. Pesticide drift: II. Mist-blower vs. aerial application of sprays. Journal of Economic Entomology, Washington, D.C., 62(4):844-846, 1969.
YATES, W.E. Spray patterns analysis and evaluation of deposits from agricultural aircraft. Transactions of the ASAE., St. Joseph, 5:40-53, 1962.

YATES, W.E. \& AKESSON, N.B. Fluorescent tracers for quantitative microresidue analysis. Transactions of the ASAE, St. Joseph, 6:104-107, 114, 1963.

YATES, W.E.; AKESSON, N.B.\& BAYER, D. Effects of spray adjuvants on drift hazards. Transactions of the ASAE, St. Joseph, 19(1):41-46, 1976.

YUILL, J.S. \& SECREST, J.P. The dye-tracer method for measuring aerial spray deposits in forest insect research. Journal of Economic Entomology, Washington, D.C., 59(3):720-723, 1966. 